\title{
Determinan Harapan Peserta Jaminan Kesehatan Nasional Terhadap Layanan Di Klinik Pratama Kota Depok Periode Mei Tahun 2016
}

\section{Determinant of JKN Member's Expectation to The Service of Primary Clinic in Depok City, May 2016}

\author{
Baiq Qurrata Aini, Rita Damayanti \\ ${ }^{1}$ Program Magister IImu Kesehatan Masyarakat, Fakultas Kesehatan Masyarakat, Universitas Indonesia, Depok \\ ${ }^{2}$ Departemen Pendidikan Kesehatan dan IImu Perilaku, Fakultas Kesehatan Masyarakat, Universitas Indonesia, Depok
}

Korespondensi: Baiq Qurrata Aini,

e-mail: qurratabaia91@gmail.com

\begin{abstract}
Abstrak
Hasil survei kepuasan peserta Jaminan Kesehatan Nasional (JKN) terhadap pelayanan klinik yang dilakukan pada tahun 2014 mencapai sekitar 80\% dan melampaui target Road Map Menuju Jaminan Kesehatan Nasional. Namun, masih banyak keluhan yang disampaikan peserta JKN seperti pada laporan YLKI, situs resmi Kemenpan, dan lain-lain. Penelitian ini bertujuan untuk mendapatkan informasi mengenai determinan harapan peserta BPJS Kesehatan terhadap layanan di Klinik Pratama Kota Depok Periode Mei Tahun 2016. Penelitian ini mengkombinasikan antara penelitian kualitatif dengan penelitian kuantitatif. Desain penelitian ini adalah sequential exploratory yang diawali dengan penelitian kualitatif dan dilanjutkan dengan penelitian kuantitatif. Dari hasil analisis data didapatkan bahwa ada hubungan antara pendidikan (nilai $p=0,02$ ), personal needs (nilai $p=0,01$ ), word-of-mouth (nilai $p=0,001$ ), dan past experience (nilai $p=0,001$ ) dengan tingkat harapan peserta BPJS terhadap layanan di klinik pratama Kota Depok periode Mei tahun 2016. Faktor yang paling dominan mempengaruhi tingkat harapan peserta BPJS terhadap layanan di klinik pratama Kota Depok periode Mei tahun 2016 adalah personal needs $(r=0,919)$. Kata Kunci: harapan peserta JKN; past experience; personal need;; words-of-mouth
\end{abstract}

\begin{abstract}
The score of JKN member's satisfaction in primary clinic in 2014 reached as high as 80\%, which means that it achieved the target of Jaminan Kesehatan Nasional's (JKN) Road Map. However, there were still many complaints coming from the BPJS customer as shown in YLKI report and in Kemenpan official website regarding unfulfillment of their expectations. This study aimed to obtain information about the determinant of member's expectation to the service of primary clinic in Depok (May 2016). This study combined qualitative and quantitative study by sequential exploratory, which was started by qualitative study to explore the phenomena and then followed by quantitative design. The number of participants in the qualitative and quantitative study were 12 and 203, respectively. The result showed that there were no correlation between gender, age, and occupation with the level of their expectation. On the other hand, there were correlation observed between the level of education, personal need, word-of-mouth, and past experience with the level of their expectation. The most dominant factor that influences the level of respondent's expectation was personal need, which means that the higher respondent frequency to visit primary clinic to get treatment when sick, the higher the level of respondent expectation.
\end{abstract}

Keyword: JKN member's expectation; personal need; past experience; words-of-mouth

\section{Pendahuluan}

Pelaksanaan UU Nomor 40 Tahun 2004 tentang Sistem Jaminan Sosial Nasional (SJSN) dan UU Nomor 24 Tahun 2011 tentang Badan Penyelenggara Jaminan Sosial (BPJS) memerlukan sinergi dari berbagai sektor. Peta Jalan (Road Map) dibuat sebagai acuan untuk mempersiapkan beroperasinya BPJS Kesehatan dan tercapainya Jaminan Kesehatan Nasional untuk seluruh penduduk Indonesia pada tahun 2019. Untuk mencapai tujuan tersebut, pada tahun 2014 telah disepakati 8 sasaran pokok yang akan dicapai salah satunya adalah paling sedikit sebanyak $75 \%$ peserta puas dengan pelayanan kese- hatan yang diterima di fasilitas kesehatan. Kepuasan peserta ditargetkan naik menjadi paling sedikit 85\% pada tahun 2019 (Dewan Jaminan Sosial Nasional, 2012).

Di Singapura, berdasarkan Patient Satisfaction Survey (PSS) 2014 yang dilakukan oleh The Ministry of Health Singapore tingkat kepuasan pasien terhadap pelayanan di rumah sakit mencapai $86 \%$ dan di klinik mencapai 92\%. Di Indonesia, survey kepuasan BPJS Kesehatan yang dilakukan oleh Myriad Research Committed di tahun 2014 menunjukkan bahwa tingkat kepuasan peserta JKN yang berobat ke 
klinik adalah sebesar $80 \%$, rumah sakit pemerintah $80 \%$, dan rumah sakit swasta $83 \%$ (BPJS Kesehatan, 2015). Hasil ini telah memenuhi target road map di tahun 2014 yang telah disusun sebelumnya. Namun, angka ini dianggap rendah bila dibandingkan dengan tingkat kepuasan pasien di Singapura, terutama untuk pasien yang berkunjung ke klinik.

Hasil survey yang dilakukan BPJS menunjukkan tingkat kepuasan peserta JKNtelah melewati target yang ditentukan, namun masih banyak keluhan yang ditemukan di lapangan. Laporan Yayasan Lembaga Konsumen Indonesia (YLKI) pada tahun 2015 mengungkapkan banyak keluhan peserta JKN terkait BPJS Kesehatan yaitu adanya diskriminasi pelayanan oleh pihak fasilitas kesehatan terhadap peserta JKN dan terdapat antrian yang sangat panjang untuk mendapatkan pelayanan kesehatan bagi peserta JKN. Hal senada juga disebutkan pada website resmi pengaduan masyarakat www.lapor.go.id (anonim, 2015) yang dikembangkan Kementrian Pendayagunaan Aparatur Negara terdapat keluhan dari masyarakat terkait masih kurangnya fasilitas di klinik pratama yang bekerjasama dengan BPJS Kesehatan.

Kepuasan didefinisikan sebagai perasaan senang maupun kecewa, sebagai hasil dari membandingkan kinerja produk yang dirasakan dengan harapan terhadap produk tersebut (Kotler \& Keller, 2009). The National Business Research Institution (NBRI) memaparkan bahwa ada beberapa dimensi yang dapat digunakan untuk mengukur kepuasan pelanggan yaitu mutu pelayanan, kecepatan pelayanan, harga, keluhan atau masalah, dan lain sebagainya (NBRI, 2009).

Mutu pelayanan merupakan perbedaan antara harapan pelanggan dan persepsi tentang pelayanan yang telah mereka terima (Parasuraman, 1988). Persepsi digambarkan sebagai opini yang terbentuk pada individu setelah merasakan pelayanan (Teas, 1993). Harapan didefinisikan sebagai pemikiran atau kepercayaan seseorang tentang kinerja yang akan diberikan dari layanan (Churchill, 1982). Harapan memainkan peran penting dalam evaluasi terhadap layanan yang dilakukan oleh pelanggan, sehingga marketers perlu memahami faktor-faktor yang membentuk harapan pelangganmereka. Marketers juga perlu memiliki kontrol atas faktor-faktor tersebut agar dapat memenuhi harapan pelanggan (Wilson et al., 2012).

Data jumlah fasilitas kesehatan di website resmi BPJS Kesehatan (www.bpjs-kesehatan.go.id) menyebutkan bahwa hingga tanggal 1 Februari
2016, tercatat 3.317 klinik pratama yang bekerja sama dengan BPJS Kesehatan di seluruh Indonesia. Kota Depok (Provinisi Jawa Barat) yang diklasifikasikan sebagai Kota Megapolitan berdasarkan Peraturan Kepala Badan Pusat Statistik Nomor 37 Tahun 2010, dengan jumlah penduduk sekitar 2.033.508 jiwa, memiliki sekitar 39 klinik pratama yang menerima peserta BPJS (Profil Kesehatan Kota Depok, 2015) dan jumlah ini diperkirakan akan terus bertambah. Klinik pratama sebagai salah satu FKTP yang pertama kali dikunjungi oleh peserta JKN harus memperhatikan mutu layanan kesehatan untuk memenuhi harapan peserta. Oleh karenanya, penelitian ini bertujuan untuk mengetahui determinan harapan peserta JKN terhadap layanan di klinik pratama di Kota Depok tahun 2016.

\section{Metodologi Penelitian}

Studi ini menggunakan metode penelitian kombinasi (mix methods research) yang menggabungkan pendekatan kualitatif dan kuantitatif (Creswell dan Clark, 2010). Desain penelitian ini adalah sequential exploratory yang diawali dengan penelitian kualitatif untuk mengeksplorasi fenomena dan dilanjutkan dengan penelitian kuantitatif. Populasi pada penelitian ini adalah peserta JKN yang terdaftar di klinik pratama Kota Depok yang terpilih sebagai tempat penelitian.

Sampel penelitian adalah peserta BPJS yang datang ke klinik pratama terpilih di Kota Depok untuk mendapatkan pelayanan kesehatan. Dalam menentukan sampel, peneliti mengambil sampel acak sederhana dengan jumlah sampel menggunakan rumus besar sampel uji hipotesis untuk proporsi populasi (Lemeshow, 1997) dan didapatkan jumlah sampel minimal sebanyak 194 responden. Untuk menghindari drop out, maka sampel ditambahkan menjadi 203 dan diambil dari empat klinik pratama di Kota Depok. Jenis data yang dikumpulkan dalam penelitian ini adalah kompilasi antara data primer dan data sekunder. Data sekunder yang digunakan adalah data harapan dan kenyataan peserta JKN terhadap layanan klinik pratama di Kota Depok. Diketahui melalui kuesioner yang disusun dan disebarkan untuk kepentingan penyusunan instrumen kepuasan peserta BPJS yang dilakukan oleh DJSN dan WHO bekerja sama dengan PPPKMI. Kuesioner ini mencakup pertanyaan dari 5 dimensi mutu yaitu, tangible, reliability, responsiveness, assurance, dan empathy.

Data primer yang dikumpulkan meliputi seluruh variabel independen seperti umur, jenis kelamin, 
pendidikan, pekerjaan, personal needs, word-of-mouth, dan past experience. Butir pertanyaan kuesioner yang berisi variabel independen (data primer) disebarkan secara bersamaan dengan kuesioner yang berisi pertanyaan tentang harapan serta kenyataan peserta JKN terhadap layanan klinik pratama di Kota Depok (data sekunder).

\section{Hasil Penelitian}

\section{Karakteristik Responden}

Berdasarkan tabel 1 dapat dilihat bahwa 119 responden $(56,6 \%)$ berusia 18 - 40 tahun dan masuk kategori dewasa lanjut. Sebanyak 130 responden (64\%) berjenis kelamin perempuan. Terdapat 77 responden (37,9\%) memiliki pendidikan terakhir setara D4/S1 atau lebih. Responden yang bekerja sebagai pekerja penerima upah (PPU) ada sebanyak 113 responden $(55,7 \%)$.

Tabel 1 Distribusi Responden Menurut Karakteristik di Kota Depok Periode Mei Tahun 2016

\begin{tabular}{lc}
\multicolumn{2}{c}{$(\mathrm{n}=203$ orang $)$} \\
\hline Variabel & $\mathbf{n}(\%)$ \\
\hline Umur & $119(56,6)$ \\
$18-40$ & $61(30)$ \\
$41-60$ & $23(11,3)$ \\
$>60$ & \\
\hline Jenis Kelamin & $73(36)$ \\
Laki-laki & $130(64)$ \\
Perempuan & \\
\hline Pendidikan & $14(6,9)$ \\
$<$ SMA & $65(32)$ \\
SMA & $47(23,2)$ \\
D1/D2/D3 & $77(37,9)$ \\
D4/S1 - Ke Atas & \\
& \\
\hline Pekerjaan & $113(55,7)$ \\
Pekerja Penerima Upah & \\
(PPU) & \\
Pekerja Bukan Penerima & $26(12,8)$ \\
Upah (PBPU) & $64(31,5)$ \\
Lainnnya & \\
\hline
\end{tabular}

\section{Gambaran Faktor yang Mempengaruhi Harapan}

Hasil penelitian kualitatif menunjukkan 7 dari 12 informan yang diwawancarai menjelaskan bahwa harapan didasari oleh pengalaman-pengalaman di masa lalu. Harapan didasari dari pengalaman menerima pelayanan kesehatan dirumah sakit, puskesmas dan klinik dan pengalaman berobat pada pelayanan kesehatan di negara lain. Harapan juga dilihat dari kebutuhan dasar para informan untuk sembuh dan sehat dan dipengaruhi oleh rekomendasi yang diber- ikan oleh orang-orang terdekat seperti saudara, teman, dan lain-lain.

Harapan responden juga didasari oleh hasil pengobatan dari suatu pusat pelayanan kesehatan. Dari hasil penelitian pendahuluan yang dilakukan melalui metode wawancara mendalam tersebut, peneliti menentukan faktor apa saja yang akan diteliti guna mengetahui determinan harapan peserta BPJS Kesehatan, sehingga faktor-faktor yang dipilih sebagai variabel independen dalam penelitan kuantitatif untuk mengetahui determinan harapan peserta BPJS Kesehatan adalah pengalaman di masa lalu (past experience), kebutuhan individu (personal needs), serta rekomendasi (word-of-mouth)

\section{Gambaran Tingkat Harapan Responden}

Dari hasil analisis didapatkan rata-rata skor tingkat harapan responden adalah 61,09 (skala $=70)$, dengan standar deviasi 6,464. Skor tingkat harapan responden terendah adalah 42 dan skor tertinggi adalah 70. Dari hasil estimasi interval dapat disimpulkan bahwa 95\% diyakini bahwa rata-rata skor tingkat harapan responden adalah adalah diantara 60,20 tahun sampai dengan 61,99 tahun (Tabel 2).

Tabel 2 Distribusi Skor Tingkat Harapan Responden $(\mathrm{n}=203$ orang) dengan skala 70

\begin{tabular}{lc}
\hline \multicolumn{1}{c}{ Parameter } & Mean \\
\hline Mean \pm SD & $61,09 \pm 6,464$ \\
Median & 59 \\
Min - Maks & $42-70$ \\
CI 95\% & $60,20-61,99$ \\
\hline
\end{tabular}

\section{Gambaran Kepuasan}

Tabel 3 Gambaran Kepuasan Responden dengan Metode Kesenjangan antara Harapan dengan Kinerja Pelayanan Aktual Klinik Pratama

\begin{tabular}{lc}
\hline Kepuasan & n (\%) \\
\hline $\begin{array}{l}\text { Puas (Nilai selisih harapan dan ken- } \\
\text { yataan } \geq 0)\end{array}$ & $85(41,9)$ \\
$\begin{array}{l}\text { Tidak Puas (Nilai selisih antara hara- } \\
\text { pan dan kenyataan }<0)\end{array}$ & $118(58,1)$ \\
\hline TOTAL & $203(100)$ \\
\hline
\end{tabular}

Tabel 3 menjelaskan kurang dari separuh (41,9\%) responden merasa puas (Nilai selisih harapan dan kenyataan $\geq 0$ ) terhadap layanan yang diberikan oleh Klinik Pratama Kota Depok pada periode Bulan Mei 2016. 
Tabel 4 Harapan Responden berdasarkan lima dimensi mutu

\begin{tabular}{|c|c|c|}
\hline Dimensi & Indikator & Mean \\
\hline \multirow{6}{*}{ Assurance } & Seluruh petugas diharapkan ramah dalam memberikan pelayanan & 4,424 \\
\hline & $\begin{array}{l}\text { Petugas kesehatan diharapkan terampil dalam memberikan } \\
\text { pengobatan }\end{array}$ & 4,424 \\
\hline & Petugas kesehatan diharapkan mampu menangani penyakit/keluhan & 4,241 \\
\hline & Pengobatan yang aman dalam menangani penyakit & 4,399 \\
\hline & Klinik ini menjaga kerahasiaan informasi pribadi & 4,384 \\
\hline & Mean Dimensi Assurance & 4,374 \\
\hline \multirow{3}{*}{ Responsiveness } & $\begin{array}{l}\text { Seluruh petugas diharapkan mampu berkomunikasi dengan lancar/ } \\
\text { baik }\end{array}$ & 4,414 \\
\hline & $\begin{array}{l}\text { Petugas kesehatan diharapkan cepat tanggap terhadap keluhan/ } \\
\text { kebutuhan pengobatan }\end{array}$ & 4,345 \\
\hline & Mean Dimensi Responsiveness & 4,379 \\
\hline \multirow[t]{3}{*}{ Empathy } & Seluruh petugas bersedia membantu menyelesaikan masalah/keluhan & 4,360 \\
\hline & Mean Dimensi Empathy & 4,360 \\
\hline & Klinik diharapkan bersih dan nyaman & 4,384 \\
\hline \multirow[t]{4}{*}{ Tangible } & $\begin{array}{l}\text { Peralatan kesehatan yang tersedia diharapkan lengkap dan berfungsi } \\
\text { dengan baik untuk mengobati penyakit }\end{array}$ & 4,369 \\
\hline & Lokasi klinik diharapkan mudah dijangkau & 4,325 \\
\hline & Mean Dimensi Tangible & 4,360 \\
\hline & $\begin{array}{l}\text { Jumlah petugas kesehatan diharapkan mencukupi kebutuhan selama } \\
\text { menjalani pengobatan }\end{array}$ & 4,300 \\
\hline \multirow[t]{3}{*}{ Reliability } & $\begin{array}{l}\text { Waktu tunggu yang diperlukan sejak mendaftar hingga memperoleh } \\
\text { pelayanan diharapkan cukup cepat (kurang dari } 1 \text { jam) }\end{array}$ & 4,300 \\
\hline & $\begin{array}{l}\text { Petugas kesehatan diharapkan menyampaikan informasi tentang } \\
\text { penyakit dan pengobatannya dengan jelas }\end{array}$ & 4,424 \\
\hline & Mean Dimensi Reliability & 4,342 \\
\hline
\end{tabular}

Tabel 5 Distribusi Responden Menurut Determinan Harapan Responden( $\mathrm{n}=203$ orang)

\begin{tabular}{|c|c|}
\hline Determinan Harapan Responden & n (\%) \\
\hline \multicolumn{2}{|l|}{$\begin{array}{l}\text { Pernah ke Klinik Lain (Past } \\
\text { Experience) }\end{array}$} \\
\hline - Pernah & $120(59,1)$ \\
\hline - Tidak Pernah & $83(40,9)$ \\
\hline \multicolumn{2}{|l|}{$\begin{array}{l}\text { Frekuensi Berobat ke Klinik Ketika } \\
\text { Sakit (Personal Need) }\end{array}$} \\
\hline - Jarang & $14(6,9)$ \\
\hline - $\quad$ Sering & $95(46,8)$ \\
\hline - Selalu & $94(46,3)$ \\
\hline \multicolumn{2}{|l|}{ Rekomendasi (Word-of-Mouth) } \\
\hline - Ada Rekomendasi & $116(57,1)$ \\
\hline - $\quad$ Tidak Ada Rekomendasi & $87(42,9)$ \\
\hline
\end{tabular}

Berdasarkan tabel 4, nilai rata-rata skor harapan tertinggi ada pada dimensi responsiveness (mean = 4,379 ) yang terdiri dari 2 indikator, yaitu kemampuan seluruh petugas dalam berkomunikasi dengan baik dan respon cepat dari petugas kesehatan dalam menanggapi keluhan dan kebutuhan pengobatan peserta BPJS Kesehatan yang menggunakan pelayanan kesehatan di Klinik Pratama Kota Depok.

\section{Determinan Harapan}

Berdasarkan tabel 5 variabel past experience, sebagian besar responden yaitu 120 orang $(59,1 \%)$ mengaku pernah berobah di klinik lain sebelum ke klinik tempat penelitian dilaksanakan. Sebanyak 950 orang (46,8\%) mengaku sering berobat ke klinik jika sakit. Sebagian besar responden yaitu 116 orang $(57,1 \%)$ berobat ke klinik pratama kota Depok dengan rekomendasi dari orang terdekat. 
Tabel 6 Hubungan Karakteristik Responden dengan Tingkat Harapan Pasien BPJS di Klinik Pratama Kota Depok Periode Mei Tahun 2016 (n=203)

\begin{tabular}{|c|c|c|c|}
\hline Variabel & Mean & SD & $\mathrm{P}$ value \\
\hline \multicolumn{4}{|l|}{ Umur } \\
\hline - $\quad 18-40$ & 61,07 & 6,455 & \\
\hline - $41-60$ & 61,70 & 6,883 & 0,417 \\
\hline - $>60$ & 59,61 & 5,255 & \\
\hline \multicolumn{4}{|l|}{ Jenis Kelamin } \\
\hline - Laki-laki & 61,08 & 6,4 & 0,985 \\
\hline - Perempuan & 61,10 & 6,5 & \\
\hline \multicolumn{4}{|l|}{ Pendidikan } \\
\hline - $\quad<$ SMA & 60,36 & 6,774 & \\
\hline - SMA & 59,40 & 6,485 & $0,002^{*}$ \\
\hline - $\quad \mathrm{D} 1 / \mathrm{D} 2 / \mathrm{D} 3$ & 60,11 & 6,301 & \\
\hline - $\mathrm{D} 4 / \mathrm{S} 1$ - keatas & 63,26 & 5,994 & \\
\hline \multicolumn{4}{|l|}{ Pekerjaan } \\
\hline - Pekerja Penerima Upah (PPU) & 61,27 & 6,663 & \\
\hline - Pekerja Bukan Penerima Upah (PBPU) & 61,96 & 6,931 & 0,549 \\
\hline - Lainnya & 60,44 & 5,933 & \\
\hline
\end{tabular}

Tabel 7 Hubungan Determinan Harapan dengan Tingkat Harapan Responden ( $\mathrm{n}=203)$

\begin{tabular}{|c|c|c|c|c|}
\hline Variabel & & Mean & SD & $\mathrm{P}$ value \\
\hline $\begin{array}{l}\text { Pengalaman Berkunjung ke Klinik Lain (Past } 1 \\
\text { - Pernah } \\
\text { - Tidak Pernah }\end{array}$ & erience) & $\begin{array}{l}62,06 \\
59,70\end{array}$ & $\begin{array}{l}6,526 \\
6,148\end{array}$ & $0,010^{*}$ \\
\hline $\begin{array}{ll}\text { Frekuensi Berobat Ke Klinik Lain (Personal Ne } \\
\text { - Jarang } \\
\text { - Sering } \\
\text { - Selalu }\end{array}$ & & $\begin{array}{l}49,36 \\
56,78 \\
67,20\end{array}$ & $\begin{array}{l}3,565 \\
1,453 \\
3,064\end{array}$ & $0,001^{* *}$ \\
\hline $\begin{array}{l}\text { Rekomendasi (Word-of-Mouth) } \\
\text { - } \quad \text { Ada Rekomendasi } \\
\text { - Tidak Ada Rekomendasi }\end{array}$ & & $\begin{array}{l}56,14 \\
67,70\end{array}$ & $\begin{array}{l}3,246 \\
2,602\end{array}$ & $0,001^{* *}$ \\
\hline $\begin{array}{r}\begin{array}{l}\text { * }=\text { bermakna signifikan secara statistik }(\mathrm{p}-\text { value }<0 \\
* *=\text { bermakna signifikan secara statistik }(\mathrm{p} \text {-value }<0\end{array} \\
\text { Tabel } 8 \text { Pemodela }\end{array}$ & Multivari & Terakhir & & \\
\hline Variabel & B & $\mathrm{P}$ value & $\mathrm{r}$ & $\mathrm{R}^{2}$ \\
\hline $\begin{array}{l}\text { Pengalaman Berkunjung ke Klinik Lain (Past } \\
\text { Experience) }\end{array}$ & 0,109 & 0,737 & 0,18 & \\
\hline Rekomendasi (Word-of-Mouth) & 4,922 & 0,001 & 0,887 & 0,883 \\
\hline $\begin{array}{l}\text { Frekuensi Berobat Ke Klinik Lain (Personal } \\
\text { Need) }\end{array}$ & 6,248 & 0,001 & 0,919 & \\
\hline
\end{tabular}


Berdasarkan hasil uji kai kuadrat pada semua variabel dalam karakteristik responden (Tabel 6) didapatkan bahwa ada hubungan antara perbedaan tingkat pendidikan dengan tingkat harapan peserta JKN di klinik pratama Kota Depok periode Mei 2016, dengan p-value $=0,002(<0,05)$. Berdasarkan hasil uji kai kuadrat (Tabel 7), variabel past experience, personal need dan word-of-mouth menunjukkan adanyahubungan dengan tingkat harapan peserta JKN.

\section{Pemodelan Multivariat Terakhir}

Berdasarkan Tabel 8, variabel independen dan variabel dependen menunjukkan hubungan yang kuat dengan $r=0,940$ (mendekati +1$)$. Nilai $R^{2}=0,883$, artinya bahwa model regresi yang diperoleh dapat menjelaskan 88,3\% variasi variabel dependen tingkat harapan peserta BPJS Kesehatan di mana kolom B menjelaskan koefisien regresi masing-masing variabel. Dari hasil di atas, persamaan regresi yang diperoleh adalah:

\section{Skor Harapan Peserta $\mathrm{JKN}=43,962+0,109$ past ex-} perience $+4,922$ word-of-mouth $+6,248$ personal need

Dengan model persamaan ini, skor harapan peserta JKNdapat diperkirakan dengan menggunakan variabel past experience, word-of-mouth, serta personal need. Adapun arti koef. B untuk masing-masing variabel independen adalah sebagai berikut:

1. Apabila peserta JKN pernah berobat ke klinik lain sebelum berobat ke klinik yang terakhir dikunjungi, maka skor harapannya rata-rata 0,109 lebih tinggi daripada peserta JKN tidak pernah berobat ke klinik lain sebelumnya, dengan asumsi status word-of-mouth (rekomendasi) dan personal needs - nya sama.

2. Apabila peserta JKN berobat ke suatu klinik berdasarkan rekomendasi orang terdekat dan dipercaya, maka skor harapannya rata-rata 4,922 lebih tinggi daripada peserta JKN berobat ke suatu klinik tanpa rekomendasi dari orang terdekat dan dipercaya, dengan asumsi status past experience (pengalaman di masa lalu) dan personal needs - nya sama.

3. Apabila peserta JKN sering berobat ke suatu klinik ketika sakit, maka skor harapannya rata-rata 6,248 lebih tinggi daripada peserta JKN yang jarang berobat ke suatu klinik ketika sakit, dengan asumsi status past experience (pengalaman di masa lalu) dan word-of-mouth - nya sama.

\section{Pembahasan}

Gambaran Faktor Yang Mempengaruhi Harapan Berdasarkan hasil penelitian kualitatif dengan metode wawancara mendalam yang dilakukan se- bagai penelitian pendahuluan, diketahui sebagian dari total informan (12 orang) mengungkapkan harapan mereka tentang waktu tunggu yang tidak lama, sistem administrasi yang tidak berbelit dan kualitas tenaga kesehatan yang mumpuni berasal dari pengalaman masa lampau (past experience) yang mereka dapatkan di tempat lain. Beberapa informan mengaku memiliki harapan seperti standar obat yang diberikan harus lebih baik dari puskesmas, pembayaran gratis karena telah menggunakan BPJS Kesehatan, serta mendapatkan pelayanan yang sama dengan pasien non BPJS Kesehatan berdasarkan kebutuhan dasar (personal need).

Informan yang berharap lebih cepat sembuh jika berobat selain di puskesmas mengaku bahwa harapan mereka tersebut berasal dari rekomendasi (word-of-mouth) dari orang-orang terdekat dan dipercaya. Ada beberapa faktor lain yang didapatkan saat melakukan proses wawancara mendalam yaitu faktor pengetahuan (enduring service intensifiers), janji implisit dari pihak penyedia layanan (implicit services promises), keadaan darurat (transitory service intensifiers), dan ketersediaan penyedia layanan lain yang menawarkan jasa sejenis sebagai perbandingan (perceived service alternatives), tetapi, faktor-faktor ini tidak diuji lebih lanjut ke dalam penelitian kuantitatif, karena tidak banyak disinggung oleh para informan. Hasil ini sesuai dengan teori yang dikemukakan oleh Zeithaml et al. (1993) yang menjelaskan bahwa past experience, personal need, dan word-ofmouth merupakan faktor-faktor yang mempengaruhi tingkat harapan.

\section{Gambaran Kepuasan Responden}

Menganalisis kepuasan tanpa melihat tingkat harapan peserta JKN, sebanyak 64\% responden (130 orang) merasa puas. Hasil tersebut menunjukkan angka yang lebih tinggi dibandingkan dengan jumlah responden yang puas menggunakan metode kesenjangan antara harapan dan kinerja pelayanan aktual yang diberikan, yaitu hanya 41,9\% (85 orang). Angka ini sangat jauh di bawah target Road Map menuju JKN yang menargetkan paling sedikit 75\% peserta puas dengan pelayanan yang diterima dari fasilitas kesehatan dan BPJS Kesehatan di tahun 2014 dan paling sedikit $85 \%$ peserta puas dengan pelayanan yang diterima dari fasilitas kesehatan dan BPJS Kesehatan di tahun 2019 (Dewan Jaminan Sosial Nasional, 2012).

Menganalisis kepuasan peserta JKN dengan melihat kesenjangan antara harapan dan kenyataan yang mereka rasakan ini sesuai dengan teori yang 
menyatakan bahwa kepuasan pelanggan dapat diukur melalui dimensi mutu layanan, yaitu dengan mengkonfirmasi atau melihat kesenjangan antara harapan serta kenyataan pelayanan yang diberikan (Churchill dan Suprenaut, 1982).

\section{Gambaran Tingkat Harapan Responden}

Rata-rata skor tingkat harapan responden yang mencapai 61,09 dari skor maksimal 70 termasuk ke dalam ideal expectations or desires, yaitu tingkat harapan yang paling tinggi dari lima kategori tingkat harapan sesuai dengan teori yang dikemukakan oleh Teas (1993). Meskipun rata-rata skor tingkat harapan responden terbilang tinggi, masih ada dua responden yang tidak berekspektasi untuk mendapatkan pelayanan yang cepat (< 60 menit) sejak mereka mendaftar. Terdapat 15 responden yang bersikap netral atau tidak berekspektasi tinggi pada poin keterjangkauan lokasi klinik dan kemampuan petugas kesehatan (dokter, suster/perawat) dalam melayani keluhan peserta JKN.

Harapan responden dianalisis berdasarkan lima dimensi sesuai dengan teori yang dikemukakan Parasuraman et al. (1988), yaitu dimensi tangible, reliability, responsiveness, assurance, dan empathy. Jika dilihat dari lima dimensi mutu, dapat dilihat bahwa nilai rata-rata skor harapan tertinggi ada pada dimensi responsiveness $($ mean $=4,379)$ yang terdiri dari 2 indikator, yaitu kemampuan petugas dalam berkomunikasi dengan baik (mean $=4,414$ ) dan respon cepat dari petugas kesehatan dalam menanggapi keluhan dan kebutuhan peserta BPJS Kesehatan $($ mean $=4,345)$.

\section{Hubungan Karakteristik Responden dengan Tingkat Harapan Responden}

Dari 4 variabel yang termasuk dalam karakteristik responden, hanya ada satu variabel yang signifikan secara statistik. Variabel tersebut adalah variabel pendidikan, yang artinya ada hubungan antara perbedaan tingkat pendidikan dengan tingkat harapan peserta JKNdi klinik pratama Kota Depok Periode mei 2016. Hal ini sesuai dengan teori yang dikemukakan oleh Sutojo dan Kleisteuber (2002) bahwa pendidikan mempengaruhi selera dan perilaku konsumen dalam mengharapkan kulitas suatu produk. Hasil penelitian Wardhana (2011) menunjukkan semakin tinggi tingkat pendidikan seseorang maka semakin tinggi harapannya dan semakin rendah tingkat kepuasannya terhadap layanan.

Teori lain yang mendukung hal inidiungkapkan oleh Zeithaml et al (1993) yang menyebutkan bahwa faktor enduring service intensifiers merupakan salah satu determinan harapan. Faktor ini merupakan faktor yang bersifat stabil dan mendorong pelanggan untuk meningkatkan sensitifitasnya terhadap jasa. Faktor ini meliputi harapan yang disebabkan oleh pengetahuan dan tingkat pendidikan seseorang.

Hubungan Determinan Harapan dengan Tingkat Harapan Responden

Dari tiga variabel (past experience, personal need, dan word-of-mouth) yang termasuk determinan harapan, seluruhnya menunjukkan hubungan dengan tingkat harapan peserta JKN di klinik pratama Kota Depok Periode Mei 2016. Hal ini sesuai dengan teori yang dikemukakan oleh Zeithaml et al. (1993) yang menyebutkan bahwa past experience (pengalaman masa lalu) meliputi hal-hal yang telah dipelajari dan diketahui oleh pelanggan pada masa sebelumnya, salah satunya pengalaman masa lampau dari menggunakan suatu produk dari provider lain yang menawarkan produk sejenis.

Pertanyaan pada kuesioner untuk mengetahui past experience responden yaitu dengan menanyakan apakah responden pernah berkunjung ke klinik lain sebelumnya atau tidak. Harapan pelanggan ini terus berkembang dari waktu ke waktu, seiring dengan semakin banyaknya informasi (non experiental information) yang diterima pelanggan dan semakin bertambahnya pengalaman baru. Pada penelitian kualitatif yang dilakukan oleh Parasuraman et al. (1985) dengan menggunakan focus group discussion (FGD) pada 12 kelompok diskusi, para informan menyebutkan bahwa pengalaman di masa lampau sering menjadi dasar bagi harapan dan evaluasi bagi mutu layanan yang diterima saat ini.

Dalam teori dari Zeithaml et al. (1993) juga disebutkan, personal needmerupakan kebutuhan mendasar yang dirasakan seseorang bagi kesejahteraannya dan sangat menentukan harapannya. Kebutuhan tersebut meliputi kebutuhan fisik, sosial dan fisiologi. Personal need seseorang dapat digambarkan dengan seberapa sering seseorang menggunakan suatu produk untuk menunjang kebutuhan dasarnya. Pertanyaan pada kuesioner untuk mengetahui personal need responden yaitu dengan menanyakan frekuensi responden berobat ke klinik ketika sakit.

Zeithaml (1993) juga mengemukakan bahwa wordof mouth, rekomendasi atau saran dari seseorang yang merupakan pernyataan (secara personal atau nonpersonal) yang disampaikan oleh orang lain selain service provider kepada pelanggan dapat mempengaruhi tingkat harapan seseorang. Poinpada kuesioner untuk mengetahui variabel word-of-mouth 
adalah dengan menanyakan apakah responden ada yang memberikan rekomendasi untuk berobat di klinik pratama tersebut atau tidak. Hasil penelitian ini juga didukung oleh hasil penelitian kualitatif Parasuraman et al. (1985) yang hanya memasukkan word-of-mouth communication, personal need, dan past experience dari 10 determinan, ke dalam determinan terhadap layanan yang diharapkan.

\section{Determinan Dominan terhadap Tingkat Hara- pan Responden}

Hasil uji multivariat didapatkan bahwa variabel yang paling mempengaruhi tingkat harapan responden adalah variabel personal need dengan nilai $\mathrm{r}$ paling tinggi yaitu 0,919 dibandingkan dengan variabel lain yang masuk pemodelan multivariat, yaitu variabel past experience $(\mathrm{r}=0,18)$ dan variabel wordsof-mouth $(\mathrm{r}=0,887)$. Dari persamaan regresi yang diperoleh, dapat diketahui bahwa apabila nilai personal need yang direpresentasikan melalui frekuensi peserta JKN berobat ke suatu klinik ketika sakit semakin tinggi, maka skor harapan peserta JKN akan naik sebesar 6,248.

\section{Kesimpulan dan Saran \\ Kesimpulan}

Kepuasan peserta JKN terhadap layanan klinik pratama Kota Depok periode Bulan Mei 2016 dengan melihat kesenjangan antara harapan dan kenyataan hanya mencapai 41,9\%. Tingkat harapan peserta JKN terhadap layanan di klinik pratama Kota Depok periode Mei tahun 2016 cukup tinggi dengan rata-rata skor tingkat harapan 61,09 (dari skala = 70). Apabila dilihat dari limadimensi mutu, dimensi responsiveness menjadi dimensi yang paling diharapkan responden. Dari hasil analisis data didapatkan bahwa ada hubungan antara pendidikan, personal needs, word-of-mouth, dan past experience dengan tingkat harapan peserta BPJS terhadap layanan di klinik pratama Kota Depok periode Mei tahun 2016. Faktor yang paling dominan mempengaruhi tingkat harapan peserta BPJS terhadap layanan di klinik pratama Kota Depok periode Mei tahun 2016 adalah personal needs.

\section{Saran}

Diharapkan Klink Pratama Kota Depok dan BPJS Kesehatan saling bekerja sama untuk lebih memperhatikan mutu pelayanan pada dimensi responsiveness dengan cara mengadakan pelatihan bagi petugas agar mampu berkomunikasi dengan baik, baik dalam masalah administrasi maupun pengobatan dan selalu memberikan respon cepat atas keluhan dan kebutu- han peserta JKN. Dinas Kesehatan Depok sebaiknya melakukan penyusunan program, monitoring dan evaluasi terhadap pemenuhan harapan peserta JKN yang memprioritaskan aspek personal needs (kebutuhan individu).

\section{Daftar Pustaka}

Anonim. 2015. Keluhan Pelayanan BPJS Kesehatan. Jakarta [19 Juni 2015]. LAPOR (Layanan Aspirasi dan Pengaduan Online Rakyat). Sitasi 26 Februari 2016 < https://www.lapor.go.id/id/1352391/ keluhan-pelayanan-bpjs-kesehatan.html>.

Andi. 2015. Fasilitas Kesehatan. Jakarta [1 Februari 2015]. BPJS Kesehatan. Sitasi 29 Februari 2016 < http://www.bpjs-kesehatan.go.id/bpjs/index.php/ pages/detail/2015/14>.

Badan Penyelenggara Jaminan Sosial Kesehatan. 2015.Survei Nasional Kepuasan Peserta Badan Penyelenggara Jaminan Sosial (BPJS) Kesehatan -2014. Jakarta.

Churchill, Gilbert A. dan Surprenant, Carol. 1982. An Investigation into The Determinants of Customer Satisfaction. Journal of Marketing Research.

Creswell, John W. dan Clark, Viki L. Plan. 2010. Designing and Conducting Mix Method Research. Sage Publications: London.

Dewan Jaminan Sosial Nasional.2012. Peta Jalan Menuju Jaminan Kesehatan Nasional. Jakarta.

(sitasi 29 Februari 2016)

(sitasi 26 Februari 2016)

Kotler, Philip dan Keller, K. L. 2009. Marketing Management: Analysis, Planning, Implementation, and Control (13th end)International Edition. Englewood Cliffs, Prentice Hall: New Jersey. Kotler, Philip, Armstrong, G., Saunders, J.,danWong, V. 2002.Principle of Marketing, 3rd Edition. Pretence Hall: New Jersey.

Kumar, M., Kee, F. T. dan Manshor, A. T. 2009. Determining the relative importance of critical factors in delivering service quality of banks; An application of dominance analysis in SERVQUAL model, Managing Service Quality, 19(2), 211228.

Lemeshow, Stanley. 1997.Besar Sampel dalam Penelitian Kesehatan. Gadjah Mada University:Yogyakarta.

NBRI. 2009. Customer Survey White Paper. http://www.nbrii.com/Customer_Surveys/Measure_ Satisfaction.html (sitasi 7 Fe bruari 2016)

Parasuraman, A., Zeithaml, Valerie A., damBerry, Leonard L. 1988. SERVQUAL: A Multiple-Item 
Scale for Measuring Consumer Perception of Service Quality. Journal of Retailing (Spring). Marketing Science Institute: Cambridge, Massachusetts.

Dinas Kesehatan Kota Depok 2015. Profil Kesehatan Kota Depok Tahun 2015. Depok: Dinas Kesehatan Kota Depok

Sutojo, Siswanto dan Kleistuber, F. 2002. Strategi Manajemen Peasaran. Penerbit Ikrar Mandiri Abadi: Jakarta.

Teas, R. K. 1993. Expectations, Performance Evaluation and Consumers' Perception of Quality. Journal of Marketing.

Wardhana, Arif Kusuma. 2011. Analisis Kepuasan
Pasien di Instalasi Rawat Inap Paviliun Kartika Jakarta Pusat Periode November 2011. Tesis. Universitas Indonesia: Jakarta.

Wilson, Alan, Zeithaml, A. Valerie, Bitner, Mary Jo, dan Gremler, Dwayne D. 2012. Service Marketing: Integrating Cutomer Focus Across The Firm Second European Edition. McGraw Hill Education: New York.

Yayasan Lembaga Konsumen Indonesia. 2015. Keluhan Masyarakat Tentang JKN. Jakarta.

Zeithaml, Valerie A., Berry, Leonard L., dan Parasuraman, A. 1993. The Nature and Determinant of Customer Expectation of Service. Journal of the Academy of Marketing Science (Winter). 